Correspondence

Ellen V. G. Frandsen

ef@microbiology.au.dk

\section{Diversity of Capnocytophaga species in children and description of Capnocytophaga leadbetteri sp. nov. and Capnocytophaga genospecies AHN8471}

\author{
Ellen V. G. Frandsen, ${ }^{1}$ Knud Poulsen, ${ }^{2}$ Eija Könönen ${ }^{3}$ and Mogens Kilian ${ }^{2}$ \\ ${ }^{1}$ Department of Oral Biology, Royal Dental College, Faculty of Health Sciences, University of \\ Aarhus, DK-8000 Aarhus C, Denmark \\ ${ }^{2}$ Institute of Medical Microbiology and Immunology, Faculty of Health Sciences, University of \\ Aarhus, DK-8000 Aarhus C, Denmark \\ ${ }^{3}$ Department of Bacterial and Inflammatory Diseases, National Public Health Institute (KTL), \\ FIN-00300 Helsinki, Finland
}

\begin{abstract}
Bacteria of the genus Capnocytophaga form part of the resident oral flora in children and adults. They are recognized as opportunistic pathogens of various extra-oral infections. The significance of individual species in periodontal and extra-oral diseases is unclear, due to the inability of conventional phenotypic tests to identify clinical isolates to species level. Aiming at a clear distinction between species, we undertook a phylogenetic study of a collection of 102 Capnocytophaga strains including 62 oral isolates from children and 40 reference strains from oral and extra-oral infections representing the five known, human, oral Capnocytophaga species. The phylogeny was estimated on the basis of multilocus enzyme electrophoresis (MLEE) of 12 intracellular, housekeeping enzymes and by partial 16S rRNA gene sequencing, and was compared to phenotypic characteristics. The clustering profiles in the MLEE and sequence-based dendrograms were concordant and allowed identification of isolates to species level, based on co-clustering with reference strains. The study confirmed Capnocytophaga ochracea and Capnocytophaga sputigena as separate species, and underlined the problems of distinguishing between them by conventional phenotypic tests. The presence of two distinct clusters of oral isolates from children indicated the existence of novel species, supported by analysis of near-full-length 16S rRNA gene sequences and by DNA-DNA hybridization results. One cluster of weakly saccharolytic isolates without the ability to ferment sucrose is proposed as Capnocytophaga leadbetteri sp. nov. (type strain AHN8855 ${ }^{\top}=$ CCUG $51857^{\top}=$ NCTC $13375^{\top}$ ). Another cluster not phenotypically distinguishable from C. ochracea and C. sputigena is designated Capnocytophaga genospecies AHN8471 (represented by strain AHN8471=CCUG $51856=$ NCTC 13374).
\end{abstract}

\section{INTRODUCTION}

Capnocytophaga species recognized as part of the human oral microbiota have been repeatedly recovered from a number of infectious diseases, e.g. septicaemia, osteomyelitis, abscesses and keratitis (Kristensen et al., 1995; Alexandrakis et al., 2000; Martino et al., 2001; Okada

Abbreviations: ET, Electrophoretic type; MLEE, multilocus enzyme electrophoresis; UPGMA, unweighted pair group method with arithmetic averages.

The GenBank/EMBL/DDBJ accession numbers for the near-full-length $16 \mathrm{~S}$ rRNA gene sequences reported in this paper are DQ009623 for strain AHN8855 ${ }^{\top}$, D0009624 for strain A0404 ${ }^{\top}$ and D0009622 for strain AHN8471. The GenBank/EMBL/DDBJ accession numbers for the other 16S rRNA gene sequences determined in this study are DQ012296-DQ012382. et al., 2002; Bonatti et al., 2003; Sabbatani et al., 2004). They are fairly often associated with infections in children with neutropenia or leukaemia (Parenti \& Snydman, 1985; Campbell \& Edwards, 1991). The three original Capnocytophaga species, Capnocytophaga ochracea, Capnocytophaga sputigena and Capnocytophaga gingivalis, were initially isolated from periodontitis in adults, but subsequent studies demonstrated their presence also at periodontally healthy sites in both children and adults. Thus, their association with periodontal disease is a matter of controversy (Dzink et al., 1988; Moore \& Moore, 1994; Colombo et al., 1998; Paster et al., 2001; Kumar et al., 2003). Early reports correlated the pathogenic potential of Capnocytophaga to an immunosuppressive effect on polymorphonuclear neutrophils, including suppression of their chemotaxis (Shurin et al., 1979; Van Dyke et al., 
1982). Subsequently, sonic extracts of Capnocytophaga were reported to inhibit lymphocyte proliferation in response to mitogen (Ochiai et al., 1998). An uneven distribution of virulence factors among isolates suggests that pathogenic potential may be associated with some of the species, and possibly only with certain members of the species (Irving et al., 1978; Laughon et al., 1982a). Especially, C. gingivalis has stronger proteolytic activity than C. ochracea and $C$. sputigena (Gazi et al., 1997), and LPS from C. gingivalis has haemagglutinating activity, in contrast to LPS from $C$. ochracea (Okuda \& Kato, 1987).

Studies of the pathogenic significance of individual Capnocytophaga species are hampered by ambiguous assignment of isolates to species level by conventional phenotypic tests (Laughon et al., 1982a; Kristiansen et al., 1984; Speck et al., 1987; Khwaja et al., 1990). The description of two novel oral species, Capnocytophaga haemolytica and Capnocytophaga granulosa, seems to have added to these difficulties (Yamamoto et al., 1994). Nevertheless, cluster analysis of RFLP patterns of 16S rRNA genes allowed differentiation between the three original species (Wilson et al., 1995), and multilocus enzyme electrophoresis (MLEE) proved to be a valuable method to distinguish between the five oral Capnocytophaga species (Frandsen \& Wade, 1996). Subsequently, oligonucleotide probes specific for all recognized Capnocytophaga species were reported (Conrads et al., 1997).

Despite improvements in potential means for identification, recent studies have revealed conflicting results regarding the Capnocytophaga species that colonize children. While a high prevalence of $C$. ochracea is a uniform finding, reports on the prevalence of $C$. gingivalis and C. sputigena vary among investigations (Conrads et al., 1996; Kamma et al., 2000a, b; Hayashi et al., 2001; Kimura et al., 2002; Ooshima et al., 2003). Moreover, a considerable diversity within the Capnocytophaga species has been demonstrated (Khwaja et al., 1990; Wilson et al., 1995; Frandsen \& Wade, 1996). To elucidate the significance of Capnocytophaga species in disease in children and adults, it is mandatory to be able to identify clinical isolates unequivocally. The present study was undertaken to test the ability of cluster analysis based on MLEE results and 16S rRNA gene sequences to identify to species level the Capnocytophaga that colonize children, and to examine the diversity of members of the genus Capnocytophaga within individual subjects. As a result of the phylogenetic and phenotypic studies we describe a novel species and a novel genospecies.

\section{METHODS}

Bacteria. The isolates included in the present study originated from oral samples of 12 children (2-3 years of age), who had been selected from a previous study of 23 children (Könönen et al., 1994) on the basis that the cultured samples yielded both yellow-orange and beige Capnocytophaga suspect colonies (Leadbetter et al., 1979). All colonies with these characteristics were selected. This resulted in 62 isolates that fulfilled the characteristics of Capnocytophaga: aerotolerance (growth in air plus $5 \% \mathrm{CO}_{2}$ or air alone), negative catalase reaction and no indole production. A range of two to nine isolates per child were investigated, including two oxidase-positive strains with characteristics that otherwise were in accordance with the original description of Capnocytophaga (Socransky et al., 1979). The isolates were considered representative of the Capnocytophaga population in the children and were given a code consisting of the prefix AHN and a number. In addition, 40 type and reference strains of the five oral human Capnocytophaga species were included. These included strains whose species affiliation had been ascertained by DNA relatedness analysis (Speck et al., 1987), as well as strains that clustered together with these strains in a dendrogram based on MLEE (Frandsen \& Wade, 1996). The species of animal origin (Capnocytophaga canimorsus and Capnocytophaga cynodegmi) were not included as reference strains because their key characteristics differ from those of the genus Capnocytophaga (Yamamoto et al., 1994). The reference strains used are shown in Table 1. All strains were cultivated on plaque agar (Jensen et al., 1968) at $37^{\circ} \mathrm{C}$ in an atmosphere of air enriched with $5 \% \mathrm{CO}_{2}$. For inspection of colonial appearance, strains were grown on modified Columbia blood agar (Hunt et al., 1986). The modifications consisted of omission of antibiotics and of the use of freeze-thawed horse blood.

MLEE. Bacterial extracts were prepared as described by Frandsen et al. (1995), except that sonication was done intermittently for $5 \mathrm{~min}$. The analyses were performed as described by Selander et al. (1986). Abbreviations of the enzyme names together with the buffer systems used according to Selander et al. (1986) are indicated in parentheses. The enzymes were: glutamate dehydrogenase (GDH, buffer system A), malate dehydrogenase $(\mathrm{MDH}, \mathrm{A})$, adenylate kinase (ADK, G), glyceraldehyde-3-phosphate dehydrogenase (GPI, G), leucyl-glycylglycyl peptidase (LGG, G), glutamic-oxaloacetic transaminase (GOT, $\mathrm{G})$, hexokinase (HEX, H), mannose-phosphate isomerase (MPI, H), nucleoside phosphorylase (NSP, I), carbamate kinase (CDK, I), phosphoglucomutase (PGM, I) and phosphoglucose isomerase (PGI, I).

Determination of genetic diversity $(h)$ at an enzyme locus among strains, i.e. the probability that two randomly chosen strains have different alleles of the locus, genetic distance between electrophoretic types (ETs), and construction of the dendrogram were performed using a matrix of pairwise genetic distances between ETs and the programs etclus and ETMEGA of T. S. Whittam, Pennsylvania State University, PA, USA (http://foodsafe.msu.edu/Whittam/programs) and MEGA version 2.1 (Kumar et al., 2001).

165 rRNA gene sequencing. Partial $16 \mathrm{~S}$ rRNA gene fragments were amplified by PCR using forward primer 5 '-AGAGTTTGATYMTGGCTCAG, positions 8-27 in the 16S rRNA gene of Escherichia coli, and reverse primer 5'-TATTACCGCGGCTGCTGGCA (positions 534515). Cells from $7 \mathrm{ml}$ liquid plaque medium (Jensen et al., 1968) were harvested, resuspended in $200 \mu$ d double-distilled water, boiled for $5 \mathrm{~min}$ and frozen. Bacterial suspension $(1 \mu \mathrm{l})$ was used as template in the PCR with Ready to Go beads (Amersham) and 10 pmol of each primer in a $25 \mu \mathrm{l}$ reaction volume. The samples were initially denatured at $94{ }^{\circ} \mathrm{C}$ for $5 \mathrm{~min}$, followed by 30 cycles at $94{ }^{\circ} \mathrm{C}$ for $1 \mathrm{~min}$, annealing at $60{ }^{\circ} \mathrm{C}$ for $1 \mathrm{~min}, 7{ }^{\circ} \mathrm{C}$ for $2 \mathrm{~min}$ and then a final extension at $72{ }^{\circ} \mathrm{C}$ for $8 \mathrm{~min}$ in a Perkin-Elmer type 480 DNA thermal cycler. The PCR products were purified using Wizard Minicolumns (Promega). Sequencing in both directions was performed with the same primers using a Thermo Sequenase dye terminator cycle sequencing kit (Amersham) and analysed on an Applied Biosystems PRISM 377 automated sequencer. The sequence read was approximately $330 \mathrm{bp}$, corresponding to a stretch from position 97 to 425 in the C. ochracea 16S rRNA gene. Phylogenetic analysis was performed as described above using the MEGA program version 2.1. Distance options were the Kimura two-parameter model and calculation of bootstrap values was based on 500 replications. 
Table 1. Reference strains used in this study

Strains were obtained from CCUG, University of Göteborg, Göteborg, Sweden; W. Mannheim, Philipps-Universität, Marburg, Germany; W. G. Wade, Dental Institute, King's College London, UK and T. Watanabe, Okayama University Dental School, Okayama, Japan.

\begin{tabular}{|c|c|}
\hline Species/strain & Source \\
\hline \multicolumn{2}{|l|}{ C. ochracea } \\
\hline CCUG $9716^{\mathrm{T}}\left(=\text { ATCC } 27872^{\mathrm{T}}\right)^{*}$ & CCUG \\
\hline CCUG $15407(=$ ATCC 33596)* & CCUG \\
\hline $779-6[=\text { Schwandt } 6 \mathrm{~b}(\mathrm{z})]^{*}$ & W. Mannheim \\
\hline 966-8 (=Mannheim 252040D $)^{*}$ & W. Mannheim \\
\hline $777-8(=\text { Schwandt } 24 \mathrm{~A})^{*}$ & W. Mannheim \\
\hline 793-5 $(=\text { CCUG 9972=VPI 13310 })^{\star}$ & W. Mannheim \\
\hline W142 & W. G. Wade \\
\hline W144 & W. G. Wade \\
\hline W250 & W. G. Wade \\
\hline W269 & W. G. Wade \\
\hline W284 & W. G. Wade \\
\hline W286 & W. G. Wade \\
\hline W291 & W. G. Wade \\
\hline W309 & W. G. Wade \\
\hline W324 & W. G. Wade \\
\hline W330 & W. G. Wade \\
\hline W363 & W. G. Wade \\
\hline W1495 & W. G. Wade \\
\hline W1496 & W. G. Wade \\
\hline W1501 & W. G. Wade \\
\hline W1511 & W. G. Wade \\
\hline E43 & Our laboratory \\
\hline N43 & Our laboratory \\
\hline $\mathrm{X} 25$ & Our laboratory \\
\hline \multicolumn{2}{|l|}{ C. sputigena } \\
\hline CCUG $9714^{\mathrm{T}}\left(=\operatorname{ATCC} 33612^{\mathrm{T}}\right)^{*}$ & CCUG \\
\hline CCUG 9277 (=VPI 13179) & CCUG \\
\hline $850-3 / 4(=$ Schmidt-Rotte B3420)* & W. Mannheim \\
\hline $907-8(=\text { Katz } 4713)^{\star}$ & W. Mannheim \\
\hline 845-1 (=Pohl B7708 $)^{\star}$ & W. Mannheim \\
\hline W264 & W. G. Wade \\
\hline W1500 & W. G. Wade \\
\hline \multicolumn{2}{|l|}{ C. gingivalis } \\
\hline CCUG $9715^{\mathrm{T}}\left(=\text { ATCC } 33624^{\mathrm{T}}\right)^{*}$ & CCUG \\
\hline $892-8(=$ Schmidt-Rotte B1392)* & W. Mannheim \\
\hline W42 & W. G. Wade \\
\hline W331 & W. G. Wade \\
\hline W336 & W. G. Wade \\
\hline N40 & Our laboratory \\
\hline $\mathrm{X} 32$ & Our laboratory \\
\hline \multicolumn{2}{|l|}{ C. granulosa } \\
\hline $\mathrm{B} 0611^{\mathrm{T}}\left(=\mathrm{JCM} 8566^{\mathrm{T}}\right)^{*}$ & T. Watanabe \\
\hline \multicolumn{2}{|l|}{ C. haemolytica } \\
\hline $\mathrm{A} 0404^{\mathrm{T}}\left(=\mathrm{JCM} 8565^{\mathrm{T}}\right)^{*}$ & T. Watanabe \\
\hline
\end{tabular}

${ }^{*}$ Species allocated by DNA-DNA relatedness.

Near-full-length $16 \mathrm{~S}$ rRNA gene sequences were determined for strains in clusters that were considered putative novel species according to the phylogenetic analyses of the MLEE and partial $16 \mathrm{~S}$
rRNA gene data. The type strain of C. haemolytica, for which the $16 \mathrm{~S}$ rRNA gene sequence was not available in databases at the time of investigation, was included. We used two primer pairs for amplification: the forward primer 5'-AGAGTTTGATYMTGGCTCAG, positions 8-27 in the E. coli $16 \mathrm{~S}$ rRNA gene, combined with the reverse primer 5' -CCGGGAACGTATTCACCG, positions 1361-1344 in the C. ochracea 16S rRNA gene, and 5'-GCATGGTTGTCGTCAGCTC, positions 1027-1045 in the C. ochracea 16S rRNA gene, combined with the reverse primer 5'-CCGGGTTTCCCCATTCGG, position 130-113 in the 23S rRNA gene of E. coli. This resulted in two overlapping fragments which covered the 16S rRNA gene, except for the first $7 \mathrm{nt}$. For sequencing we used the same primers and six additional primers. The forward primers were 5 '-ACGGGAGGCAGCAGT, positions 343-357 in the E. coli $16 \mathrm{~S}$ rRNA gene, $5^{\prime}$-ATTAGATACCCTGGTAG (positions 785-802) and 5'-GGAATCGCTAGTAATCG (positions 1336-1352). The reverse primers were 5 '-CTCACTGCTGCCTCCCGT, positions 348-330 in the C. ochracea $16 \mathrm{~S}$ rRNA gene, $5^{\prime}$-CTACCAGGGTATCTAATC, positions 802-785 in the E. coli $16 \mathrm{~S}$ rRNA gene, and 5'-GAGCTGACGACAACCATGC, positions 1045-1027 in the C. ochracea 16S rRNA gene. 16S rRNA gene sequences of the type strains of $C$. ochracea (GenBank accession no. U41350), C. sputigena (X67609), C. gingivalis (X67608), C. granulosa (U41348), C. canimorsus (L14637) and C. cynodegmi (L14638) were taken from GenBank. Alignments of the 16S rRNA gene sequences to those of the respective type strains and calculation of identity were performed with the BLAST program (http:// www.ncbi.nlm.nih.gov) (Tatusova \& Madden, 1999).

DNA-DNA relatedness and DNA G+C content assays. DNA was isolated using a French pressure cell (Thermo Spectronic) and was purified by chromatography on hydroxyapatite (Cashion et al., 1977). DNA-DNA hybridization was carried out as described by De Ley et al. (1970) with modifications (Huß et al., 1983; Escara \& Hutton, 1980), using a model 2600 spectrophotometer equipped with a model 2527$\mathrm{R}$ thermoprogrammer and plotter (Gilford Instrument Laboratories). Renaturation rates were computed with the TRANSFER.BAS program of Jahnke (1992). The DNA G +C content was determined by the HPLC method described by Tamaoka \& Komagata (1984) with the modifications described by Mesbah et al. (1989). The experiments were performed at the Deutsche Sammlung von Mikroorganismen und Zellkulturen GmbH, Braunsweig, Germany.

Biochemical tests. All strains and isolates were tested for haemolysis on horse blood agar and for oxidase activity. Fermentation of carbohydrates was evaluated both as a colour change induced in phenol red broth base and as a $\mathrm{pH}$ drop measured in trypticase broth (Socransky et al., 1979), each supplemented with $1 \%$ of the following sugar substrates: amygdalin, arabinose, cellobiose, fructose, galactose, glucose, lactose, raffinose, sucrose and xylose. The $\mathrm{pH}$ measurements were evaluated as indicated by Socransky et al. (1979): a pH drop $\geqslant 1.0$ units below the $\mathrm{pH}$ of both the uninoculated carbohydrate broth and the inoculated carbohydrate-free broth controls was recorded as a positive fermentation. A pH drop between 0.5 and 0.99 units was recorded as a weak fermentation, and a $\mathrm{pH}$ change of less than 0.5 units was considered negative. Hydrolysis of aesculin and starch was tested according to Cowan (1974). Dextran hydrolysis was measured by the method of Staat et al. (1973). The ability to produce $\beta$-galactosidase (ONPG) and $N$-acetyl- $\beta$-glucosaminidase and to degrade $N$-benzoyl-DL-arginine-2-naphthylamide was detected as described previously (Kilian, 1978; Laughon et al., 1982b). API ZYM enzyme-substrate tests were performed as recommended by the manufacturer (bioMérieux). A score of $3-5$, corresponding to $\geqslant 20 \mathrm{nmol}$ of substrate hydrolysed, was recorded as a positive reaction and a score of $1-2$, corresponding to 5-20 nmol, was recorded as weakly positive. The following tests were performed on selected strains: hydrolysis of gelatin [incubation for 7 and 14 days at $37^{\circ} \mathrm{C}$, followed by refrigeration as described by Cowan (1974)] and 


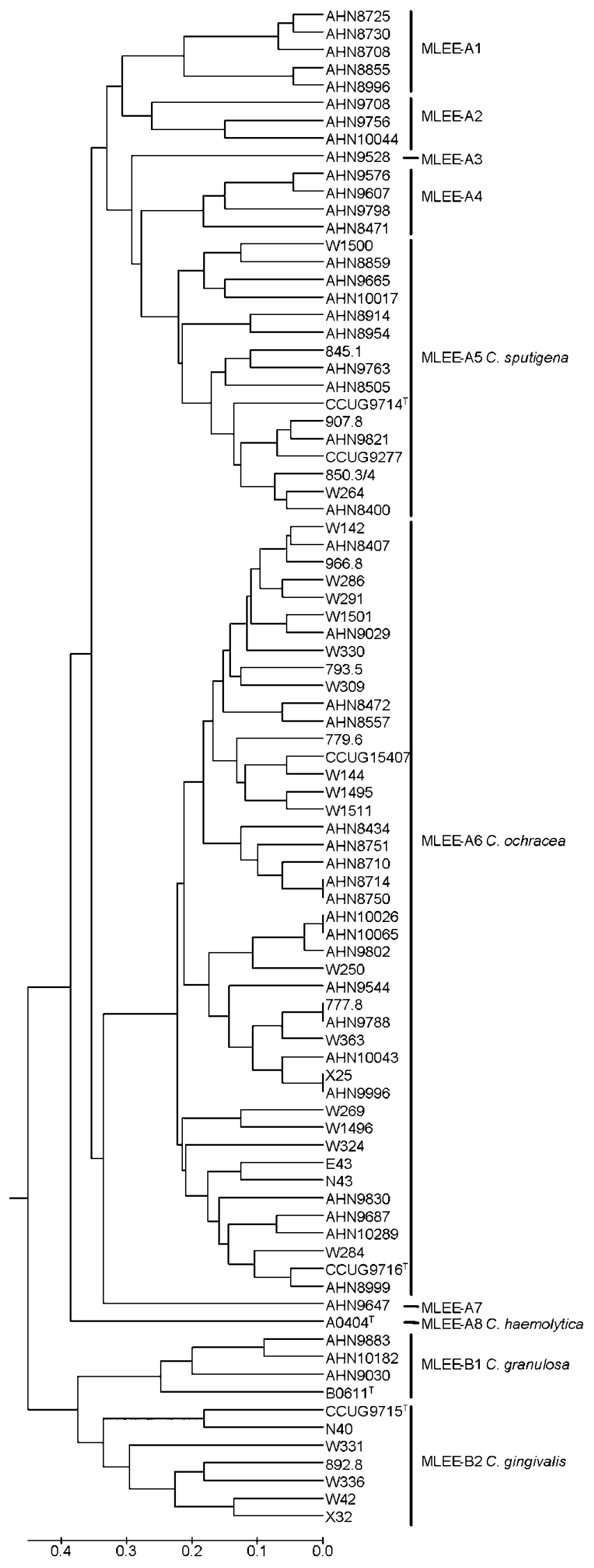

urea (Kilian, 1985), reduction of nitrate using freshly prepared indole-nitrite medium (BBL) supplemented with haemin and menadione as described by Holdeman et al. (1977) and fermentation of glycogen, inulin, melibiose and starch (Socransky et al., 1979). To test for human IgA1 cleavage, human dimeric IgA1 from a patient (Kah) with multiple myeloma, purified as described previously (Frandsen, 1994), was used. Bacterial colonies were suspended in $40 \mu \mathrm{l}$ of $1 \mathrm{mg} \operatorname{IgAl~ml} \mathrm{m}^{-1}$ solution and subjected to immunoelectrophoresis after incubation for $24 \mathrm{~h}$ at $36{ }^{\circ} \mathrm{C}$ (Kilian, 1981).

\section{RESULTS}

\section{MLEE analysis}

Electrophoretic mobility of 12 intracellular enzymes was assayed in all 102 isolates and reference strains. For calculation of genetic diversity and construction of an unweighted pair group method with arithmetic averages (UPGMA) dendrogram based on the MLEE data, 16 isolates with an ET identical to one of the other isolates from the same child were omitted because they represented repeated isolation of the same clone. All enzymes were polymorphic, with a mean number of 6.9 (range 3-13) alleles per locus. The mean genetic diversity $(h)$ per locus was 0.65 (range $0.15-0.88$ ). Absence of activity for the enzymes GOT and HEX in some strains was previously shown to be species-related (Frandsen \& Wade, 1996). Treating the absence of enzyme activity for these two enzymes as either missing data or as a signifying 'zero allele' resulted in identical clustering of strains in the MLEE dendrograms.

Fig. 1 presents the UPGMA tree based on MLEE data. The reference strains of the five recognized human Capnocytophaga species clustered in the same subdivisions as observed previously (Frandsen \& Wade, 1996), supporting the usefulness of MLEE for species differentiation in this genus. The MLEE dendrogram revealed two major lineages, termed divisions MLEE-A and MLEE-B, each of which showed several subdivisions (marked in Fig. 1). A negative reaction for the enzyme HEX and a positive reaction for the enzyme GOT were characteristic of strains in MLEE-B1 (C. granulosa cluster) and MLEE-B2 ( $C$. gingivalis cluster). All other isolates and strains were positive for HEX and negative for GOT, except for AHN9647 and AHN10017 from division A, which were positive for GOT.

Fig. 1. Phylogenetic tree (UPGMA) based on MLEE data. As only one representative strain of each ET per individual was included in the dendrogram, the following 16 strains are not shown: AHN8436 (=AHN8407), AHN8430 and AHN8560 (=AHN8400), AHN8506 (=AHN8472), ANH8727 and AHN8721 (=AHN8714), AHN9043 (=AHN9029), AHN8995 (=AHN8859), AHN9685 (=AHN9544), AHN9792 (=AHN9788), AHN9828 and AHN9872 (=AHN9821), $\mathrm{AHN} 9831$ and AHN9834 (=AHN9830), AHN10300 and AHN10306 (=AHN 10289). Bar, distance of 0.1, which represents a difference in 1.2 of the 12 enzymes tested. 
The clustering indicated that 20 child isolates (plus 12 duplicates) belonged to the species C. ochracea (MLEE-A6 in Fig. 1) and nine isolates (plus four duplicates) belonged to C. sputigena (MLEE-A5 in Fig. 1). Three child isolates clustered with C. granulosa, whereas no $C$. gingivalis or $C$. haemolytica isolates were found. A total of 14 isolates clustered independently of the clusters that represented recognized species. These were located in the following clusters: MLEE-A1 (five isolates), MLEE-A2 (three isolates), MLEE-A3 (one isolate), MLEE-A4 (four isolates) and MLEE-A7 (one isolate) (Fig. 1). Despite the limited number of isolates from each child, intra-subject diversity was observed (Table 2).

\section{$16 S$ rRNA gene sequencing}

To elucidate further the species affiliation of the child isolates that clustered separately from recognized species, partial $16 \mathrm{~S}$ rRNA gene sequencing was performed for all 102 isolates and strains. Some of the $16 \mathrm{~S}$ rRNA gene sequences showed ambiguity indicative of nucleotide polymorphism among multiple copies of the 16S rRNA gene. For construction of the sequence-based (SEQ) dendrograms, 15 isolates were omitted because they represented repeated isolation of the same clone from the same child. They were identical to those omitted in the MLEE dendrograms, except for AHN9831, which was retained in the SEQ-analyses because it had a unique sequence compared with the other isolates from the same individual.

Fig. 2 presents the neighbour-joining tree based on partial (approx. $330 \mathrm{bp)} \mathrm{16S} \mathrm{rRNA} \mathrm{gene} \mathrm{sequences} \mathrm{(SEQ-tree).}$ The maximum-parsimony tree showed essentially the same topology (data not shown). The SEQ dendrogram also consisted of two divisions, SEQ-A and SEQ-B, each of which showed a number of subdivisions. The clustering profile of the SEQ dendrogram had an overall similarity to the profile of the MLEE dendrogram. The differences observed did not represent stable clusters according to bootstrap values (Fig. 2).

Scattered throughout subdivisions SEQ-A6-8 and SEQA10 were the type strain of $C$. ochracea and reference strains that had been assigned to C. ochracea, not only on the basis of MLEE analysis but also on the basis of both phenotypic tests and DNA-DNA relatedness results. The W309 sequence (SEQ-A2) included only $299 \mathrm{nt}$ because the first part of the sequence was unreadable irrespective of the sequence direction, presumably due to sequence polymorphism among the rRNA operons. This may explain its position in the tree, remote from the other $C$. ochracea reference strains. Strain W331 (clustering with $C$. gingivalis in the MLEE dendrogram) showed a closer relationship to the C. granulosa group in the SEQ dendrogram, supported by the $85 \%$ bootstrap value of this branching from the $C$. gingivalis group. The clusters SEQ-A1, SEQ-A3, SEQ-A5 and SEQ-B1 exclusively contained child isolates. Cluster SEQ-A1 was not supported by a significant bootstrap value and included child isolates that clustered with $C$. ochracea in the MLEE dendrogram. SEQ-A3 included the same five child isolates as MLEE-A3 and -A4 with a sequence similarity exceeding $99.5 \%$, plus AHN8751 from MLEE-A6. SEQ-A5 contained five strains from MLEE-A1 and one strain, AHN9708, from MLEE-A2 (sequence similarity exceeding 99.5\%). Isolate AHN9647 constituted a separate lineage in both dendrograms (MLEE-A7 and SEQ-B1).

Based on the phylogenetic analyses of data from MLEE and partial $16 \mathrm{~S}$ rRNA gene sequencing, three evolutionary lineages could represent putative novel species, as none of them included recognized type strains and they separated from other clusters at the same level as recognized species. SEQ-B1 contained only one isolate; it was therefore not investigated further. SEQ-A3 contained strains AHN8471,

Table 2. Identity and diversity in ETs of Capnocytophaga species in 12 children

\begin{tabular}{|c|c|c|c|c|c|c|}
\hline \multirow[t]{2}{*}{ Child } & \multicolumn{6}{|c|}{ Species (no. of isolates/no. of ETs of each taxon) } \\
\hline & C. ochracea & C. sputigena & C. granulosa & Taxon AHN8471 & Taxon AHN8855 & Capnocytophaga sp.* \\
\hline A & $3 / 2$ & $2 / 1$ & & & & \\
\hline B & $4 / 2$ & 1 & & 1 & & \\
\hline C & $5 / 3$ & & & 1 & $3 / 3$ & \\
\hline $\mathrm{D}$ & $2 / 1$ & $2 / 2$ & 1 & & & \\
\hline $\mathrm{E}$ & 1 & $2 / 1$ & & & $2 / 2$ & \\
\hline F & 1 & & & & & 1 \\
\hline G & $2 / 1$ & & & 1 & & $2 / 2$ \\
\hline $\mathrm{H}$ & & 1 & & $2 / 2$ & & $2 / 2$ \\
\hline I & $2 / 1$ & 1 & & & & \\
\hline $\mathrm{K}$ & $3 / 2$ & $3 / 1$ & 1 & & & \\
\hline $\mathrm{L}$ & $4 / 4$ & 1 & 1 & & & 1 \\
\hline $\mathrm{M}$ & $3 / 1$ & & & & & \\
\hline
\end{tabular}

${ }^{\star}$ Isolates that could be assigned neither to one of the existing species nor to one of the two novel taxa. 


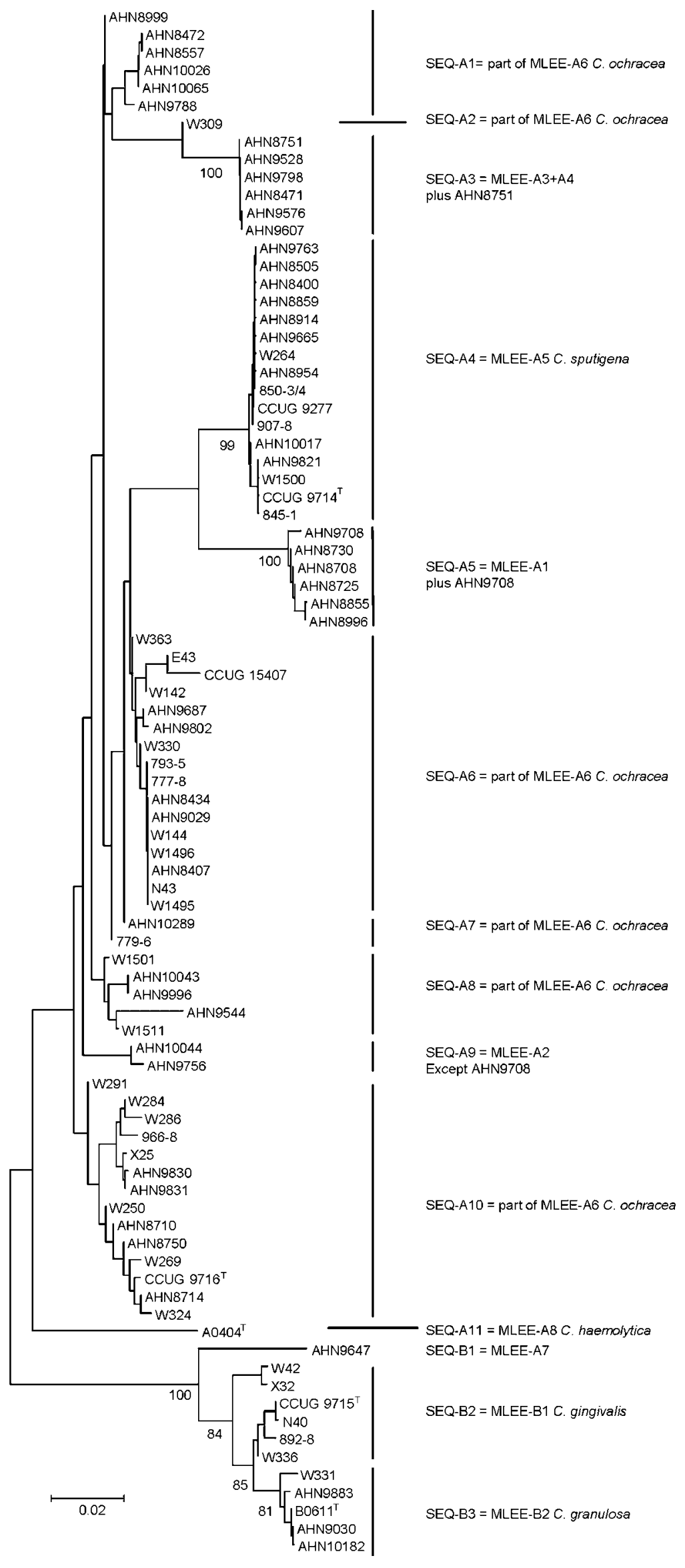

Fig. 2. Phylogenetic tree (neighbour-joining method) based on partial (approx. $330 \mathrm{bp}$ ) 16S rRNA gene sequences. As only one representative strain per individual of each sequence-type was included in the dendrogram, the strains omitted from the MLEE tree, except for strain AHN9831, were also omitted here. Bootstrap values $>50 \%$ based on 500 replications indicated. Bar, $2 \%$ difference in sequence. 
AHN9528, AHN9576, AHN9607 and AHN9798, which clustered in MLEE-A3 + A4, plus AHN8751 from MLEEA6. SEQ-A5 contained strains AHN8855, AHN8708, AHN8725, AHN8730 and AHN8996, which clustered in MLEE-A1, plus AHN9708 from MLEE-A2.

Fig. 3 presents the neighbour-joining tree based on nearly full-length 16S rRNA gene sequencing of the abovementioned strains together with the type strain of $C$. haemolytica $\left(\mathrm{A} 0404^{\mathrm{T}}\right.$ ) (Fig. 3). The 16S rRNA gene sequence of all strains included 1484-1491 bp, except for strain AHN8730 which, due to ambiguous sequences, was not readable beyond position 1331. The strains within each of the two novel taxa showed $99 \%$ mutual similarity (no gaps). The closest relatives to both taxa were $C$. ochracea and $C$. sputigena ( $95 \%$ similarity and $8-10$ gaps). Lower sequence similarities $(\leqslant 92 \%)$ were found to all other described species of the genus Capnocytophaga, including the animal species C. cynodegmi and C. canimorsus, and to the strains in the other novel taxon. Strain AHN9708 from MLEE-A2 and SEQ-A5 was lost before near-full-length sequencing and DNA relatedness analyses. Strains AHN10044 and AHN9756 from MLEE-A2 had only $96 \%$ similarity (0-1 gap) to the strains in SEQ-A5.

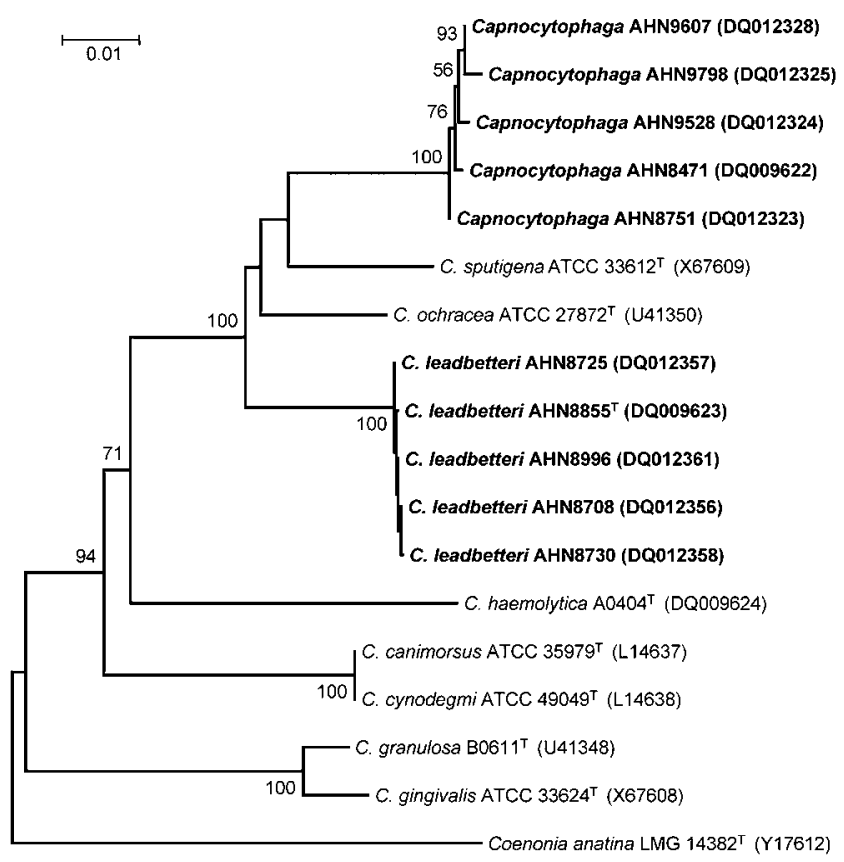

Fig. 3. Phylogenetic tree (neighbour-joining method) based on near-full-length 16S rRNA gene sequences of the strains of the two putative novel taxa and type strains of existing Capnocytophaga species, including the type strains of $C$. canimorsus and C. cynodegmi, and Coenonia anatina. Bootstrap values $>50 \%$ based on 500 replications are indicated. GenBank accession numbers are given in parentheses. Bar, $1 \%$ difference in sequence.

\section{DNA-DNA relatedness, DNA $G+C$ content and taxonomic considerations}

Strains AHN8471 and AHN8855 ${ }^{\mathrm{T}}$ were selected as representatives of the two putative novel species. They showed a low level of DNA relatedness to each other $(40.7 \%)$ and to type strains of the five known human oral Capnocytophaga species (18.0-42.4\% for AHN8471 and $16.6-43.5 \%$ for $A H N 8855^{\mathrm{T}}$ ). Of the five isolates clustering with AHN8471 in SEQ-A3, three showed DNA relatedness above $70 \%$, the threshold suggested for species identity (Wayne et al., 1987). AHN9528 approached this threshold $(68.6 \%)$ and had a significantly lower relatedness to the type strains of both C. ochracea (33.6\%) and C. sputigena $(51.8 \%)$, for this reason it was considered part of the new taxon. The taxonomic position of the remaining isolate, AHN9576, was uncertain due to a combination of low DNA relatedness and high 16S rRNA gene sequence similarity to AHN8471. Consequently, it was considered aberrant. In addition to strain AHN8471, taxon AHN8471 consisted of AHN9528, AHN9607, AHN9798 and AHN8751. The four isolates clustering with AHN8855 in both the MLEE and the SEQ dendrograms showed DNA relatedness from 72.0 to $75.6 \%$. AHN9708 from MLEE-A2 was lost before these experiments and was thus unavailable for analyses and AHN10044 and AHN9756, also from MLEE-A2, had low values of DNA relatedness $(<42 \%)$. In addition to AHN8855 ${ }^{\mathrm{T}}$, taxon AHN8855 consisted of AHN8708, AHN8725, AHN8730 and AHN8996. The DNA $\mathrm{G}+\mathrm{C}$ content of AHN8471 was $38.8 \mathrm{~mol} \%$ and that of AHN8855 ${ }^{\mathrm{T}}$ was $41.3 \mathrm{~mol} \%$.

\section{Biochemical characterization}

With the purpose of identifying phenotypic tests suitable for species differentiation, all 102 isolates and reference strains of human oral Capnocytophaga species were subjected to a battery of 37 biochemical tests, the results of which are presented in Table 3 . The isolates and strains representing the individual species are those that clustered unequivocally with the type and reference strains in both the MLEE and the SEQ dendrograms. The results for $C$. haemolytica are based on the type strain only. In agreement with the original description of the species, this strain had lost its $\beta$-haemolytic activity (Yamamoto et al., 1994). The species C. cynodegmi and C. canimorsus were not included in Table 3 because these are animal species and are reported to be distinct from human Capnocytophaga species by positive catalase and oxidase reactions (Brenner et al., 1989). Strains and isolates in the present study were negative in catalase and oxidase reactions, except for WW331 and AHN9647, which were positive for oxidase. Twenty of the tests showed variations among isolates (Table 3). Of these, a minor proportion was suitable for species differentiation: acid production from cellobiose, amygdalin and sucrose, dextran hydrolysis and tests for trypsin-like (hydrolysis of $\mathrm{N}$-benzoyl-DL-arginine2-naphthylamide) and $\beta$-glucosaminidase activities when 


\section{Table 3. Biochemical characteristics of the human Capnocytophaga species}

Species: 1, C. leadbetteri sp. nov. (type strain AHN8855 ${ }^{\mathrm{T}}$ results are in parentheses); 2, Capnocytophaga genospecies AHN8471; 3, C. ochracea; 4, C. sputigena; 5, C. gingivalis; 6, C. granulosa; 7, C. haemolytica. +, Positive; -, negative; w, weakly positive; v, variable results. The numbers are the percentage of positive/weakly positive strains in a species with variable reactions. All data are from this study. All strains were positive for the following API ZYM tests: alkaline phosphatase, leucyl and valine aminopeptidases (except for A0404 ${ }^{\mathrm{T}}$, which was negative), acid phosphatase and $\alpha$ glucosidase. All strains were negative for haemolysis on horse blood agar, fermentation of xylose, fermentation of arabinose (except AHN9798, which was weakly positive) and oxidase activity (except AHN9647, which showed variable results, and W331, which was repeatedly positive) and were negative for the following API ZYM tests: $\beta$-glucuronidase (except for the weakly positive reaction of AHN8730, AHN9708 and B0611), $\alpha$ mannosidase (except for the weakly positive reaction of AHN8708 and 777-8) and $\alpha$-fucosidase. C-14 lipase and $\alpha$-galactosidase activities ranged from negative to weakly positive, with no connection to species.

\begin{tabular}{|c|c|c|c|c|c|c|c|}
\hline No. of strains & 5 & 5 & 42 & 16 & 6 & 5 & 1 \\
\hline \multicolumn{8}{|l|}{ Fermentation of: } \\
\hline Cellobiose & $-(-)$ & $40 / 20$ & $88 / 7$ & $6 / 0$ & $17 / 0$ & - & - \\
\hline Fructose & $0 / 20(-)$ & $80 / 0$ & $76 / 0$ & $38 / 6$ & $33 / 0$ & $20 / 0$ & - \\
\hline Galactose & $0 / 20(w)$ & + & $98 / 0$ & $44 / 13$ & $17 / 0$ & $20 / 0$ & + \\
\hline Lactose & $0 / 40(w)$ & $80 / 20$ & $95 / 0$ & $56 / 13$ & $33 / 0$ & + & + \\
\hline Raffinose & $-(-)$ & $80 / 0$ & $95 / 0$ & $44 / 25$ & $83 / 0$ & $0 / 20$ & + \\
\hline Sucrose & $-(-)$ & + & $93 / 0$ & $56 / 13$ & + & + & + \\
\hline \multicolumn{8}{|l|}{ Hydrolysis of: } \\
\hline Aesculin & $-(-)$ & $20 / 0$ & $67 / 0$ & $44 / 0$ & - & $40 / 20$ & + \\
\hline Dextran & $-(-)$ & + & $79 / 0$ & $87 / 6$ & - & - & - \\
\hline $\begin{array}{l}\text { C8-esterase } \\
\text { lipase }\end{array}$ & $+(\mathrm{w})$ & $0 / 100$ & $11 / 30$ & $38 / 56$ & $17 / 83$ & $0 / 100$ & + \\
\hline $\begin{array}{l}\text { Cystine } \\
\text { arylamidase }\end{array}$ & $40 / 40(+)$ & $60 / 20$ & $69 / 31$ & + & + & + & - \\
\hline Trypsin & $-(-)$ & $0 / 60$ & $5 / 36$ & $0 / 38$ & + & $0 / 60$ & + \\
\hline$\alpha$-Chymotrypsin & $40 / 0(w)$ & $40 / 60$ & $29 / 67$ & $19 / 69$ & $17 / 67$ & $0 / 20$ & $\mathrm{w}$ \\
\hline Acid phosphatase & $60 / 40(+)$ & $80 / 20$ & $98 / 2$ & $81 / 19$ & $17 / 83$ & $80 / 20$ & + \\
\hline$\beta$-Galactosidase & $40 / 60(+)$ & $20 / 60$ & $36 / 62$ & $38 / 50$ & $17 / 17$ & $60 / 20$ & $\mathrm{w}$ \\
\hline$\beta$-Glucosidase & $20 / 0(-)$ & $20 / 60$ & $17 / 60$ & $0 / 19$ & $0 / 33$ & $80 / 0$ & - \\
\hline $\begin{array}{l}N \text {-Acetyl- } \beta \text { - } \\
\text { glucosaminidase }\end{array}$ & $+(+)$ & + & + & + & $0 / 50$ & - & + \\
\hline IgAl cleavage & $+(+)$ & + & $93 / 0$ & $94 / 0$ & $67 / 0$ & $80 / 0$ & - \\
\hline
\end{tabular}

${ }^{\star}$ Positive and negative reactions were obtained with repeated tests.

performed in the API ZYM kit. The two latter tests had a much higher sensitivity, leading to more positive reactions when they were performed with alternative chromogenic substrates (data not shown). This was also the case for $\beta$ galactosidase (ONPG) activity, where all strains were positive when performed with alternative chromogenic substrates.

Differentiation between C. ochracea and C. sputigena was difficult, with cellobiose fermentation having the highest discriminatory power. The $\beta$-glucosidase test might also be useful. Moreover, two isolates with identical ET and $16 \mathrm{~S}$
rRNA gene sequences from an individual could vary in the phenotypic tests. The C. gingivalis and C. granulosa group was distinguished from the C. ochracea and C. sputigena group by fermentation of amygdalin and hydrolysis of dextran. Discrimination between $C$. gingivalis and $C$. granulosa was difficult, fermentation of lactose and raffinose and presence of trypsin-like and $\beta$-glucosidase activities being the best choices. Taxon AHN8855 consisted of strains with weak saccharolytic activity. Lack of fermentation of sucrose had the highest discriminatory power from the other species. Taxon AHN8471 could not be distinguished from the $C$. ochracea and C. sputigena 
group by means of the phenotypic tests included in Table 3 . Additional tests selected from the proposed minimal standard tests for describing new taxa in the genus Capnocytophaga (Bernardet et al., 2002) were performed on the strains from taxon AHN8471 and two reference strains each of C. ochracea (CCUG $9716^{\mathrm{T}}$ and CCUG 15407) and C. sputigena (CCUG 9714 ${ }^{\mathrm{T}}$ and CCUG 9277). None of the strains hydrolysed gelatin or urea, reduced nitrate or fermented melibiose. All strains fermented glycogen and starch, and all strains, except AHN8471, fermented inulin. Thus, inclusion of these additional tests did not result in differential tests for taxon AHN8471. Strains from taxon AHN8855 reduced nitrate, and tests for hydrolysis of gelatin and urea and fermentation of melibiose, glycogen, starch and inulin were negative, except for AHN8730, which fermented starch and inulin.

Upon primary isolation on Brucella blood agar, colonies of the strains belonging to taxon AHN8855 were beige (Könönen et al., 1994). We found that this feature was variable and depended on the substrate. On plaque agar plates (Jensen et al., 1968) containing haemolysed blood, the colonial appearance varied from beige to yellow-orange and pink. On Columbia blood agar containing defibrinated freeze-thawed blood (modified from Hunt et al., 1986), the colonial appearance varied from beige to yellow-orange, green or pink. Strains belonging to taxon AHN8471 produced typical yellow-orange or green colonies on fresh plates of plaque agar and Columbia blood agar, whereas use of 10-day-old plates for inoculation resulted in beige colonies for some strains.

Of the 102 isolates and strains tested, 93 (91\%) cleaved human IgA1 in a pattern typical of IgA1 protease activity, as revealed by immunoelectrophoresis (Table 3 ).

\section{DISCUSSION}

Correct identification to the species level is mandatory for determination of the significance of individual members of the genus Capnocytophaga in health and disease. For the present study, a collection of 102 Capnocytophaga strains were subjected to phylogenetic and taxonomic investigations. The child isolates originated from 12 children selected from a larger study of 23 children (Könönen et al., 1994) because oral sample cultures yielded growth of Capnocytophaga 'suspect' colonies of both yellow-orange and beige appearance. Despite the inclusion of both colony types, a limited number of Capnocytophaga isolates (mean 5.5, range 2-9) were recovered from each child. This supports the findings of others that, although Capnocytophaga bacteria are found in a large proportion of young children, they are not prominent members of the oral flora (Könönen et al., 1994; Conrads et al., 1996; Kamma et al., 2000a, b; Hayashi et al., 2001; Kimura et al., 2002; Ooshima et al., 2003).

Lack of oxidase activity was originally described as a defining feature of the genus Capnocytophaga (Socransky et al., 1979). Brenner et al. (1989) reported animal strains that produced oxidase but otherwise resembled Capnocytophaga species and, on this basis, described them as two Capnocytophaga species. The unequivocal affiliation to the genus of two oxidase-positive strains (AHN9647 and W331) in this study on the basis of partial 16S rRNA gene sequences (98\% identity to other Capnocytophaga $16 \mathrm{~S}$ rRNA gene sequences) confirms that the oxidase test is not reliable for discrimination of the genus from related genera.

The usefulness of MLEE for differentiation between Capnocytophaga species was confirmed in the present study and extended to include the two new taxa, taxon AHN8471 and taxon AHN8855. Moreover, presence of the enzyme GOT and absence of the enzyme HEX discriminated $C$. granulosa and C. gingivalis from the other Capnocytophaga species.

Interpretation of MLEE results is based on the assumption that differences in mobility of individual enzymes reflect differences in protein sequence and thus a genetic difference. This is less precise than nucleotide sequencing and, as a consequence of sequencing becoming faster and less expensive, MLEE is losing its significance. In this respect, however, it is noteworthy that MLEE proved much better at identifying C. ochracea (Fig. 1) than partial sequencing of the $16 \mathrm{~S}$ rRNA gene (Fig. 2).

The existence of three new taxa was indicated by the MLEE and the SEQ dendrograms. We refrained from investigating further the MLEE-A7/SEQ-B1 subdivision because it contained only a single isolate (AHN9647) and as such it did not merit an elevation to species rank. Taxon AHN8471 and taxon AHN8855 consisted of several isolates from four and two children, respectively, and thus warranted further investigation. The near-full-length $16 \mathrm{~S}$ rRNA gene sequences (Fig. 3) and DNA-DNA relatedness studies confirmed that the two taxa represent novel species.

Based on a combination of clustering in the MLEE and SEQ-based dendrograms, a threshold of $97 \% 16 \mathrm{~S}$ rRNA gene similarity and a threshold of $70 \%$ DNA-DNA relatedness for species identity (Stackebrandt \& Goebel, 1994; Wayne et al., 1987), each of the two taxa contained five strains. AHN9528 showed only $68.6 \%$ DNA-DNA relatedness to strain AHN8471, but belonged to taxon AHN8471 by all other analyses and was consequently retained in the taxon. Strain AHN9576 was more distantly related to AHN8471 (55.1\% DNA-DNA relatedness), for which reason it was not included in the taxon. The taxonomic status of this strain remains a puzzle because it appeared to be closely related to the other strains in this cluster according to both dendrograms. Collectively, these results emphasize that the species affiliation of an isolate should be based on several different analyses.

The phenotypic examination of the strains in our collection confirmed the difficulties in distinguishing between Capnocytophaga species (Laughon et al., 1982a; 
Kristiansen et al., 1984; Khwaja et al., 1990). Especially, distinction between $C$. ochracea and $C$. sputigena is difficult, prompting others to stop using phenotypic tests for species identification (Ciantar et al., 2005). The limited usefulness of phenotypic tests for these two species was underscored by the finding of variations in test results in duplicate isolates from the same individual that otherwise presented with identical ET and partial 16S rRNA gene sequences. Taxon AHN8471 increased the problems of species differentiation. Additional tests selected from the proposed minimal standard tests for describing new taxa in the genus Capnocytophaga (Bernardet et al., 2002) were included in order to search for tests that allow differentiation of taxon AHN8471 from C. ochracea and C. sputigena. For the majority of these tests, variations among strains belonging to the same species were previously reported (Socransky et al., 1979; Kristiansen et al., 1984; Speck et al., 1987; Yamamoto et al., 1994). This clearly illustrates the difficulties in species differentiation within the genus Capnocytophaga by traditional phenotypic analysis.

The heterogeneity in the genus Capnocytophaga has puzzled researchers for a long time and is probably a major reason why the association between members of this genus and periodontal disease remains an open question. Application of genetic analyses in future studies may facilitate clarification of the role of these bacteria in disease (Gevers et al., 2005).

We found by far the highest prevalence of $C$. ochracea and C. sputigena in young Finnish children. C. granulosa and C. haemolytica were originally isolated from supragingival plaque in adults (Yamamoto et al., 1994) and later recovered from subgingival plaque from adults as well (Ciantar et al., 2001). For C. granulosa, this may now be extended to include the oral cavity of children. In addition, taxon AHN8471 and taxon AHN8855 were isolated, but at low frequencies. C. gingivalis was not found. The latter observation is in contrast to other studies. In Greek children with primary dentition, C. ochracea was found in $40 \%$, C. gingivalis in $55.8 \%$ and C. sputigena in $2.5 \%$ of the samples, according to speciation by conventional phenotypic tests (Kamma et al., 2000b). Based on PCR with species-specific primers, the prevalence of the three species in periodontally healthy Japanese children was $100 \%$ for C. ochracea, $96 \%$ for C. gingivalis and $48 \%$ for C. sputigena (Hayashi et al., 2001). Kimura et al. (2002) using the same technique found $C$. ochracea and $C$. sputigena in approximately $50 \%$ of Japanese children with primary dentition. This study did not include $C$. gingivalis in the analysis. In addition to the employment of different identification criteria, the differences between the studies, especially with regard to $C$. gingivalis, may be due to racial and/or geographical differences.

Search for rRNA gene sequences from non-cultivated bacteria (http://rdp.cme.msu.edu/index.jsp) that matched the partial rRNA gene sequences of the strains belonging to the two novel species revealed a $100 \%$ match for the sequences of three of the strains of $C$. leadbetteri to sequence AY807298 and a $99.1 \%$ match for two of the Capnocytophaga genospecies AHN8471 strains to sequence AY806644. Both of these sequences originated from an airway sample of a child with cystic fibrosis (GenBank data). The partial sequences of three of the C. leadbetteri strains showed a $97.7-99.7 \%$ match to sequence AY005075, and three of the Capnocytophaga genospecies AHN8471 strains revealed a $96.6 \%$ match to sequence AY005076. Both of these sequences originated from a human subgingival plaque sample (Paster et al., 2001).

The results of this study facilitate more unequivocal assignment of clinical isolates of the genus Capnocytophaga to species level and create a platform for future studies of the clinical significance of the individual species and of potential differences in pathogenic potential between and within the species.

\section{Description of Capnocytophaga genospecies AHN8471}

Due to lack of an easily performed phenotypic test, we describe taxon AHN8471 as Capnocytophaga genospecies AHN8471. Cells are slender $(0.35-0.45 \times 3-5 \mu \mathrm{m})$, Gramnegative rods, motile by gliding. Yellow-orange or green colonies, 1-2 $\mathrm{mm}$ in diameter, appear 2-3 days after anaerobic incubation on fresh plaque agar and Columbia blood agar plates. Pellets of cells grown anaerobically in liquid culture are orange. Grows in air enriched with $5 \%$ $\mathrm{CO}_{2}$, but not in air alone. Tests for catalase, indole, oxidase, $\beta$-haemolysis on blood agar, hydrolysis of gelatin and urea, reduction of nitrate and fermentation of melibiose are negative. All strains ferment glycogen and starch, and all strains except AHN8471 ferment inulin. Other phenotypic characteristics are presented in Table 3. The genospecies is not distinguishable from $C$. ochracea and C. sputigena by means of traditional phenotypic tests. However, MLEE and partial 16S rRNA gene sequencing are useful for differentiation. All strains cleave human IgA1 in the hinge region.

The reference strain is AHN8471 (=CCUG 51856=NCTC 13374 ) and has a $\mathrm{G}+\mathrm{C}$ content of $38.8 \mathrm{~mol} \%$. Other strains belonging to the genospecies are AHN8751, AHN9528, AHN9607 and AHN9798. All strains have been isolated from the oral cavity of children.

\section{Description of Capnocytophaga leadbetteri sp. nov.}

Capnocytophaga leadbetteri [lead.bet'te.ri. N.L. gen. masc. n. leadbetteri of Leadbetter, in honour of E. R. Leadbetter, the American microbiologist who (as first author) described and proposed the genus Capnocytophaga].

Cells are slender $(0.35-0.45 \times 3-5 \mu \mathrm{m})$, Gram-negative rods motile by gliding. Colonies $1-2 \mathrm{~mm}$ in diameter and ranging from beige to yellow-orange or pink appear 
2-3 days after anaerobic incubation on plaque agar. On Columbia blood agar, the colonial appearance varies from beige to yellow-orange, green or pink. Pellets of cells grown anaerobically in liquid culture are beige. Grows in air enriched with $5 \% \mathrm{CO}_{2}$, but not in air alone. Tests for catalase, indole, oxidase, $\beta$-haemolysis on blood agar, hydrolysis of gelatin and urea and fermentation of melibiose, glycogen, starch and inulin are negative, except for AHN8730, which ferments starch and inulin. All strains reduce nitrate. Other phenotypic characteristics, including the specific reactions of the type strain, are presented in Table 3. The species consists of strains with weak saccharolytic activity. Lack of fermentation of sucrose has the highest discriminatory power from other species. MLEE and partial 16S rRNA gene sequencing are also useful for species differentiation. All strains cleave human IgAl in the hinge region.

The type strain is AHN8855 ${ }^{\mathrm{T}}$ (=CCUG $51857^{\mathrm{T}}=\mathrm{NCTC}$ $13375^{\mathrm{T}}$ ) and has a DNA G + C content of $41.3 \mathrm{~mol} \%$. Other strains belonging to the species are AHN8708, AHN8725, AHN8730 and AHN8996. All strains have been isolated from the oral cavity of children.

\section{ACKNOWLEDGEMENTS}

The technical assistance of Lene Friis, Bente Hansen and Lise Hald is gratefully acknowledged. The study was supported by the Foundation of the Danish Dental Association for Scientific and Practical Investigations in the Art of Dentistry, The Foundation for Promotion of Scientific and Practical Dentistry and the Research Foundation of the University of Aarhus (grants no. E-2000-SUN-1165 and F-2001-SUN-1-71).

\section{REFERENCES}

Alexandrakis, G., Palma, L. A., Miller, D. \& Alfonso, E. C. (2000). Capnocytophaga keratitis. Ophthalmology 107, 1503-1506.

Bernardet, J.-F., Nakagawa, Y. \& Holmes, B. (2002). Proposed minimal standards for describing new taxa of the family Flavobacteriaceae and emended description of the family. Int J Syst Evol Microbiol 52, 1049-1070.

Bonatti, H., Rossboth, D. W., Nachbaur, D., Fille, M., Aspock, C., Hend, I., Hourmont, K., White, L., Malnick, H. \& Allerberger, F. J. (2003). A series of infections due to Capnocytophaga spp. in immunosuppressed and immunocompetent patients. Clin Microbiol Infect 9, 380-387.

Brenner, D. J., Hollis, D. G., Fanning, G. R. \& Weaver, R. E. (1989). Capnocytophaga canimorsus sp. nov. (formerly CDC group DF-2), a cause of septicaemia following $\operatorname{dog}$ bite, and Capnocytophaga cynodegmi sp. nov., a cause of localized wound infection dog bite. J Clin Microbiol 27, 231-235.

Campbell, J. R. \& Edwards, M. S. (1991). Capnocytophaga species infections in children. Pediatr Infect Dis J 10, 944-948.

Cashion, P., Holder-Franklin, M. A., McCully, J. \& Franklin, M. (1977). A rapid method for the base ratio determination of bacterial DNA. Anal Biochem 81, 461-466.

Ciantar, M., Spratt, D. A., Newman, H. N. \& Wilson, M. (2001). Capnocytophaga granulosa and Capnocytophaga haemolytica, novel species in subgingival plaque. J Clin Periodontol 28, 701-705.
Ciantar, M., Newman, H. N., Wilson, M. \& Spratt, D. A. (2005). Molecular identification of Capnocytophaga spp. via 16S rRNA PCRrestriction fragment length polymorphism analysis. J Clin Microbiol 43, 1894-1901.

Colombo, A. P., Haffajee, A. D., Dewhirst, F. E., Paster, B. J., Smith, C. M., Cugini, M. A. \& Socransky, S. S. (1998). Clinical and microbiological features of refractory periodontitis subjects. J Clin Periodontol 25, 169-180.

Conrads, G., Mutters, R., Fischer, J., Brauner, A., Lutticken, R. \& Lampert, F. (1996). PCR reaction and dot-blot hybridization to monitor the distribution of oral pathogens within plaque samples of periodontally healthy individuals. J Periodontol 67, 994-1003.

Conrads, G., Mutters, R., Seyfarth, I. \& Pelz, K. (1997). DNA-probes for the differentiation of Capnocytophaga species. Mol Cell Probes 11, 323-328.

Cowan, S. J. \& Steel, K. J. (1974). Cowan and Steel's Manual for the Identification of Medical Bacteria, 2nd edn. London: Cambridge University Press.

De Ley, J., Cattoir, H. \& Reynaerts, A. (1970). The quantitative measurement of DNA hybridization from renaturation rates. Eur $J$ Biochem 12, 133-142.

Dzink, J. L., Socransky, S. S. \& Haffajee, A. D. (1988). The predominant cultivable microbiota of active and inactive lesions of destructive periodontal diseases. J Clin Periodontol 15, 316-323.

Escara, J. F. \& Hutton, J. R. (1980). Thermal stability and renaturation of DNA in dimethyl sulfoxide solutions: acceleration of the renaturation rate. Biopolymers 19, 1315-1327.

Frandsen, E. V. (1994). Carbohydrate depletion of immunoglobulin A1 by oral species of gram-positive rods. Oral Microbiol Immunol $\mathbf{9}$, 352-358.

Frandsen, E. V. \& Wade, W. G. (1996). Differentiation of human Capnocytophaga species by multilocus enzyme electrophoretic analysis and serotyping of immunoglobulin A1 proteases. Microbiology 142, 441-448.

Frandsen, E. V., Poulsen, K. \& Kilian, M. (1995). Confirmation of the species Prevotella intermedia and Prevotella nigrescens. Int J Syst Bacteriol 45, 429-435.

Gazi, M. I., Cox, S. W., Clark, D. T. \& Eley, B. M. (1997). Characterization of protease activities in Capnocytophaga spp., Porphyromonas gingivalis, Prevotella spp., Treponema denticola and Actinobacillus actinomycetemcomitans. Oral Microbiol Immunol 12, 240-248.

Gevers, D., Cohan, F. M., Lawrence, J. G., Spratt, B. G., Coeney, T., Feil, E. J., Stackebrandt, E., Van de Peer, Y., Vandamme, P. \& other authors (2005). Re-evaluating prokaryotic species. Nat Rev Microbiol 3, 733-739.

Hayashi, F., Okada, M., Zhong, X. \& Miura, K. (2001). PCR detection of Capnocytophaga species in dental plaque samples from children aged 2 to 12 years. Microbiol Immunol 45, 17-22.

Holdeman, L. V., Cato, E. P. \& Moore, W. E. C. (1977). Anaerobe Laboratory Manual, 4th edn. Blacksburg, VA: Virginia Polytechnic Institute and State University Anaerobe Laboratory.

Hunt, D. E., Jones, J. V. \& Dowell, V. R., Jr (1986). Selective medium for the isolation of Bacteroides gingivalis. J Clin Microbiol 23, 441-445.

Huß, V. A. R., Festl, H. \& Schleifer, G. (1983). Studies on the spectrophotometric determination of DNA hybridization from renaturation rates. Syst Appl Microbiol 4, 184-192.

Irving, J. T., Socransky, S. S. \& Tanner, A. C. (1978). Histological changes in experimental periodontal disease in rats monoinfected with gram-negative organisms. J Periodontal Res 13, 326-332. 
Jahnke, K. D. (1992). BASIC computer program for evaluation of spectroscopic DNA renaturation data from GILFORD SYSTEM 2600 spectrophotometer on a PC/XT/AT type personal computer. J Microbiol Methods 15, 61-73.

Jensen, S. B., Löe, H., Schiött, C. R. \& Theliade, E. (1968). Experimental gingivitis in man. 4. Vancomycin induced changes in bacterial plaque composition as related to development of gingival inflammation. J Periodontal Res 3, 284-293.

Kamma, J. J., Diamanti-Kipioti, A., Nakou, M. \& Mitsis, F. J. (2000a). Profile of subgingival microbiota in children with mixed dentition. Oral Microbiol Immunol 15, 103-111.

Kamma, J. J., Diamanti-Kipioti, A., Nakou, M. \& Mitsis, F. J. (2000b). Profile of subgingival microbiota in children with primary dentition. J Periodontal Res 35, 33-41.

Khwaja, K. J., Parish, P., Aldred, M. J. \& Wade, W. G. (1990). Protein profiles of Capnocytophaga species. J Appl Bacteriol 68, 385-390.

Kilian, M. (1978). Rapid identification of Actinomycetaceae and related bacteria. J Clin Microbiol 8, 127-133.

Kilian, M. (1981). Degradation of immunoglobulins A1, A2, and G by suspected principal periodontal pathogens. Infect Immun 34, 757-765.

Kilian, M. (1985). Haemophilus. In Manual of Clinical Microbiology, 4th edn, pp. 387-383. Edited by E. H. Lennette, A. Balows, W. J. Hausler, Jr \& H. J. Shadomy. Washington, DC: American Society for Microbiology.

Kimura, S., Ooshima, T., Takiguchi, M., Sasaki, Y., Amano, A., Morisaki, I. \& Hamada, S. (2002). Periodontopathic bacterial infection in childhood. J Periodontol 73, 20-26.

Könönen, E., Asikainen, S., Saarela, M., Karjalainen, J. \& JousimiesSomer, H. (1994). The oral gram-negative anaerobic microflora in young children: longitudinal changes from edentulous to dentate mouth. Oral Microbiol Immunol 9, 136-141.

Kristensen, B., Schönheyder, H. C., Peterslund, N. A., Rosthoj, S., Clausen, N. \& Frederiksen, W. (1995). Capnocytophaga (Capnocytophaga ochracea group) bacteremia in hematological patients with profound granulocytopenia. Scand J Infect Dis 27, 153-155.

Kristiansen, J. E., Bremmelgaard, A., Busk, H. E., Heltberg, O., Frederiksen, W. \& Justesen, T. (1984). Rapid identification of Capnocytophaga isolated from septicemic patients. Eur J Clin Microbiol 3, 236-240.

Kumar, S., Tamura, K., Jakobsen, I.-B. \& Nei, M. (2001). MEGA2: molecular evolutionary genetics analysis software. Bioinformatics 17, 1244-1245.

Kumar, P. S., Griffen, A. L., Barton, J. A., Paster, B. J., Moeschberger, M. L. \& Leys, E. J. (2003). New bacterial species associated with chronic periodontitis. J Dent Res 82, 338-344.

Laughon, B. E., Syed, S. A. \& Loesche, W. J. (1982a). API ZYM system for identification of Bacteroides spp., Capnocytophaga spp. and spirochetes of oral origin. J Clin Microbiol 15, 97-102.

Laughon, B. E., Syed, S. A. \& Loesche, W. J. (1982b). Rapid identification of Bacteroides gingivalis. J Clin Microbiol 15, 345-346.

Leadbetter, E. R., Holt, S. C. \& Socransky, S. S. (1979). Capnocytophaga: new genus of gram-negative gliding bacteria. I. General characteristics, taxonomic considerations and significance. Arch Microbiol 122, 9-16.

Martino, R., Ramila, E., Capdevila, J. A., Planes, A., Rovira, M., Ortega, M., Plume, G., Gomez, L. \& Sierra, J. (2001). Bacteremia caused by Capnocytophaga species in patients with neutropenia and cancer: results of a multicenter study. Clin Infect Dis 33, E20-E22.

Mesbah, M., Premachandran, U. \& Whitman, W. B. (1989). Precise measurement of the $\mathrm{G}+\mathrm{C}$ content of deoxyribonucleic acid by highperformance liquid chromatography. Int J Syst Bacteriol 39, 159-167.
Moore, W. E. \& Moore, L. V. (1994). The bacteria of periodontal diseases. Periodontol 2000 5, 66-77.

Ochiai, K., Senpuku, H. \& Kurita-Ochiai, T. (1998). Purification of immunosuppressive factor from Capnocytophaga ochracea. J Med Microbiol 47, 1087-1095.

Okada, M., Awane, S., Suzuki, J., Hino, T., Takemoto, T., Kurihara, H. \& Miura, K. (2002). Microbiological, immunological and genetic factors in family members with periodontitis as a manifestation of systemic disease, associated with hematological disorders. J Periodontal Res 37, 307-315.

Okuda, K. \& Kato, T. (1987). Hemagglutinating activity of lipopolysaccharides from subgingival plaque bacteria. Infect Immun 55, 3192-3196.

Ooshima, T., Nishiyama, N., Hou, B., Tamura, K., Amano, A., Kusumoto, A. \& Kimura, S. (2003). Occurrence of periodontal bacteria in healthy children: a 2-year longitudinal study. Community Dent Oral Epidemiol 31, 417-425.

Parenti, D. M. \& Snydman, D. R. (1985). Capnocytophaga species: infections in nonimmunocompromised and immunocompromised hosts. J Infect Dis 151, 140-147.

Paster, B. J., Boches, S. K., Galvin, J. L., Ericson, R. E., Lau, C. N., Levanos, V. A., Sahasrabudhe, A. \& Dewhirst, F. E. (2001). Bacterial diversity in human subgingival plaque. J Bacteriol 183, 3770-3783.

Sabbatani, S., Manfredi, R., Frank, G. \& Chiodo, F. (2004). Brain abscess in an immunocompetent host: problems in antimicrobial chemotherapy and literature review. J Chemother 16, 497-501.

Selander, R. K., Caugant, D. A., Ochman, H., Musser, J. M., Gilmour, M. N. \& Whittam, T. S. (1986). Methods of multilocus enzyme electrophoresis for bacterial population genetics and systematics. Appl Environ Microbiol 51, 873-884.

Shurin, S. B., Socransky, S. S., Sweeney, E. \& Stossel, T. P. (1979). A neutrophil disorder induced by Capnocytophaga, a dental microorganism. N Engl J Med 301, 849-854.

Socransky, S. S., Holt, S. C., Leadbetter, E. R., Tanner, A. C., Savitt, E. \& Hammond, B. F. (1979). Capnocytophaga: new genus of gramnegative gliding bacteria. III. Physiological characterization. Arch Microbiol 122, 29-33.

Speck, H., Kroppenstedt, R. M. \& Mannheim, W. (1987). Genomic relationships and species differentiation in the genus Capnocytophaga. Zentralbl Bakteriol Mikrobiol Hyg [A] 266, 390-402.

Staat, R. H., Gawronski, T. H. \& Schachtele, C. F. (1973). Detection and preliminary studies on dextranase-producing microorganisms from human dental plaque. Infect Immun 8, 1009-1016.

Stackebrandt, E. \& Goebel, B. M. (1994). Taxonomic note: a place for DNA-DNA reassociation and $16 \mathrm{~S}$ rRNA sequence analysis in the present species definition in bacteriology. Int J Syst Bacteriol 44, 846-849.

Tamaoka, J. \& Komagata, K. (1984). Determination of DNA base composition by reversed-phase high-performance liquid chromatography. FEMS Microbiol Lett 25, 125-128.

Tatusova, T. A. \& Madden, T. L. (1999). BLAST 2 Sequences, a new tool for comparing protein and nucleotide sequences. FEMS Microbiol Lett 174, 247-250.

Van Dyke, T. E., Bartholomew, E., Genco, R. J., Slots, J. \& Levine, M. J. (1982). Inhibition of neutrophil chemotaxis by soluble bacterial products. J Periodontol 53, 502-508.

Wayne, L. G., Brenner, D. J., Colwell, R. R., Grimont, P. A. D., Kandler, O., Krichevsky, M. I., Moore, L. H., Moore, W. E. C., Murray, R. G. E. \& other authors (1987). International Committee on Systematic Bacteriology. Report of the ad hoc committee on reconciliation of approaches to bacterial systematics. Int J Syst Bacteriol 37, 463-464. 
Wilson, M. J., Wade, W. G. \& Weightman, A. J. (1995). Restriction fragment length polymorphism analysis of PCR-amplified $16 \mathrm{~S}$ ribosomal DNA of human Capnocytophaga. J Appl Bacteriol 78, 394-401.
Yamamoto, T., Kajiura, S., Hirai, Y. \& Watanabe, T. (1994). Capnocytophaga haemolytica sp. nov. and Capnocytophaga granulosa sp. nov., from human dental plaque. Int $J$ Syst Bacteriol 44, 324-329. 